\title{
Erratum to: Primary Network Interference Compensation-Based Dynamic Spectrum Leasing and Secondary Network Power Control
}

\author{
Wen-jiang Feng • Weiheng Jiang
}

Published online: 14 January 2015

C Springer Science+Business Media New York 2015

\section{Erratum to: Wireless Pers Commun DOI 10.1007/s11277-014-2261-6}

The first author's name was spelled incorrectly in the original publication. The correct name is Wen-jiang Feng, as shown in this erratum.

The online version of the original article can be found under doi:10.1007/s11277-014-2261-6.

W. Feng · W. Jiang $(\bowtie)$

College of Communication Engineering, Chongqing University,

Chongqing 400044, China

e-mail: whjiang@cqu.edu.cn 